\title{
In silico analysis of promoter region and regulatory elements of glucan endo-1,3- beta-glucosidase encoding genes in Solanum tuberosum: cultivar DM 1-3 516 R44
}

\author{
Atnafu Kebede ${ }^{1,2^{*}}$ (iD) and Mulugeta Kebede ${ }^{1}$
}

\begin{abstract}
Background: Potato (Solanum tuberosum L.) is one of the most important food crops in the world. Pathogens remain as one of the major constraints limiting potato productivity. Thus, understanding of gene regulation mechanism of pathogenesis-related genes such as glucan endo-1,3-beta-glucosidase is a foundation for genetic engineering of potato for disease resistance and reduces the use of fungicides. In the present study, 19 genes were selected and attempts were made through in silico methods to identify and characterize the promoter regions, regulatory elements, and CpG islands of glucan endo-1,3-beta-glucosidase gene in Solanum tuberosum cultivar DM 1-3 516 R44.

Results: The current analysis revealed that single transcription start sites (TSSs) were present in 12/19 (63.2\%) of promoter regions analyzed. The predictive score at a cutoff value of 0.8 for the majority (84.2\%) of the promoter regions ranged from 0.90 to 1.00 . The locations for $42 \%$ of the TSSs were below -500 bp relative to the start codon (ATG). M $\beta G$ Il was identified as the common promoter motif for $94.4 \%$ of the genes with an $E$ value of $3.5 \mathrm{e}-001$. The CpG analysis showed low CpG density in the promoter regions of most of the genes except for gene ID102593331 and ID: 102595860. The number of SSRs per gene ranged from 2 to 9 with repeat lengths of 2 to 6 bp. Evolutionary distances ranged from 0.685 to 0.770 (mean $=0.73$ ), demonstrating narrower genetic diversity range. Phylogeny was inferred using the UPGMA method, and gene sequences from different species were found to be clustered together.

Conclusion: In silico identified regulatory elements in promoter regions will contribute to our understanding of the regulatory mechanism of glucan endo-1,3-beta-glucosidase genes and provide a promising target for genetic engineering to improve disease resistance in potatoes.
\end{abstract}

Keywords: Solanum tuberosum, Glucan endo-1,3-beta-glucosidase, CpG island, Motif, Promoter, Transcription factor

\footnotetext{
* Correspondence: atnafukebede@yahoo.com

'Department of Applied Biology, School of Applied Natural Science, Adama Science and Technology University, P.O. Box 1888, Adama, Ethiopia

${ }^{2}$ Department of Biology, College of Natural and Computational Sciences, Dire Dawa University, P.O. Box 1362, Dire Dawa, Ethiopia
}

\section{Springer Open}

(c) The Author(s). 2021 Open Access This article is licensed under a Creative Commons Attribution 4.0 International License, which permits use, sharing, adaptation, distribution and reproduction in any medium or format, as long as you give appropriate credit to the original author(s) and the source, provide a link to the Creative Commons licence, and indicate if changes were made. The images or other third party material in this article are included in the article's Creative Commons licence, unless indicated otherwise in a credit line to the material. If material is not included in the article's Creative Commons licence and your intended use is not permitted by statutory regulation or exceeds the permitted use, you will need to obtain permission directly from the copyright holder. To view a copy of this licence, visit http://creativecommons.org/licenses/by/4.0/. 


\section{Background}

Potato (Solanum tuberosum L.) is one of the most widely consumed carbohydrate-rich staple foods in large parts of the world; it is the fourth largest food crop in production [1]. Potato is mainly used as a staple food, but it also has a number of medicinal values. Moderate consumption of the juice from the tubers is used in the treatment of peptic ulcers, bringing relief from pain and acidity [2].

Pathogenesis-related proteins, often called PR proteins, are a structurally diverse group of plant proteins that are toxic to invading fungal pathogens. They are widely distributed in plants in trace amounts, but are produced in much greater concentrations following pathogen attack or stress. PR proteins exist in plant cells intracellularly and also in the intercellular spaces, particularly in the cell walls of different tissues. Varying types of PR proteins have been isolated from each of several crop plants. Different plant organs, e.g., leaves, seeds, and roots, may produce different sets of PR proteins. Different PR proteins appear to be expressed differentially in their hosts in the field when temperatures become stressful, low or high, for extended periods [3].

The several groups of PR proteins have been classified according to their function, serological relationship, amino acid sequence, molecular weight, and certain other properties. PR proteins are either extremely acidic or extremely basic and therefore are highly soluble and reactive. At least 14 families of PR proteins are recognized. Among these pathogenesis-related proteins, glucan endo-1,3-beta-glucosidases ( $\beta$-1,3-glucanases) are one important hydrolytic enzyme that is abundant in many plant species after infection by different types of pathogens. The amount of them significantly increases and plays a major role in defense reaction against fungal pathogens by degrading the cell wall, because $\beta-1,3-$ glucan is a structural component of the cell walls of many pathogenic fungi. Glucan endo-1,3-beta-glucosidase appears to be coordinately expressed along with chitinases after fungal infection. This co-induction of the two hydrolytic enzymes has been described in many plant species, including pea, bean, tomato, tobacco, maize, soybean, potato, and wheat [4-11]. In addition to their roles in pathogen defense, glucan endo-1,3-beta-glucosidases have been implicated in cell division, pollen development, pollen tube growth, regulation of plasmodesmata signaling, cold response, seed germination, and maturation [12].

Glucan -1,3-beta-glucosidase forms highly complex and diverse gene families in plants, and a single plant species may have various copies of glucan-1,3-beta-glucosidase genes [12]. The glucan -1,3-beta-glucosidases are the enzymes which can cleave the beta glycosidic linkages of glucans. They can be divided into two groups, exo or endo. The exo-hydrolases catalyze the hydrolysis of the beta-glucan chain by sequentially cleaving glucose residues from the non-reducing end and releasing glucose as the sole hydrolysis product. The endohydrolases cleave $\beta$-linkages at apparently random sites along the polysaccharide chain, releasing smaller oligosaccharides [13]. The enzyme glucan-1,3-beta-glucosidase is important to delay the growth of pathogenic fungi and to decrease the damage caused by disease in fruits. The application of this enzyme is possible due to the composition of the cell walls of certain microorganisms which contain $\beta$-glucans [14].

Many studies have shown that the synthesis of glucan endo-1,3-beta-glucosidase is stimulated when plants are infected by fungal, bacterial, or viral pathogens, and its concentration also increases dramatically. For instance, mRNA for a tomato glucan endo-1,3-beta-glucosidase accumulated to a higher level in leaves infected with the fungal pathogen Cladosporium fulvum [15], barley infected with powdery mildew [16], maize infected with Aspergillus flavus [17], pepper infected with Phytophthora capsici, wheat infected with Fusarium graminearum [11], chickpea infected with Ascochyta rabiei (Pass.) Labr [18]., and peach infected with Monilinia fructicola [19]. Scientists throughout the world have tried to analyze or predict the regulatory elements of pathogen-related genes in higher plants whose expression products have an inhibitory effect on microorganisms such as fungi. However, only a small percentage of PR genes have been investigated.

To the best of our knowledge, there is no report that evaluates the regulatory elements of glucan endo-1,3beta-glucosidase genes in potato (Solanum tuberosum L). Moreover, owing to the crucial roles of glucan endo1,3-beta-glucosidase genes in the plant defense system, it is imperative to understand and analyze the promoter region and regulatory elements of glucan endo-1,3-betaglucosidase genes in Solanum tuberosum. The knowledge will contribute to our understanding of the expression profiles and regulatory mechanism of glucan endo1,3-beta- glucosidase genes. It also provides a promising target for genetic engineering for improved glucan endo1,3-glucosidase expression in potato and uplifts the level of defense response in potato against fungal pathogens and develops disease-resistant transgenic potato, which is an environmentally friendly approach of a disease control method.

\section{Methods}

A total of 27 whole genome shotgun gene sequences of glucan endo-1,3-beta-glucosidase for Solanum tuberosum cultivar DM 1-3 516 R44 were retrieved from the NCBI database available at https://www.nlm.nih.gov/ gene; of these, 19 of them were selected for analysis, 
while the remaining eight gene sequences were excluded from this analysis because they were not having the functional gene structure (many stop codons appear in the middle and the reading frame was highly fragmented), after checking with CLC Genomics Workbench ver. 3.6.1 (http://clcbio.com, CLC bio, Aarhus, Denmark) (Table 1).

\section{Finding of transcription start sites and determination of promoter sequence}

Glucan endo-1,3-beta-glucosidase gene sequences of Solanum tuberosum cultivar DM 1-3 516 R44 were downloaded in FASTA file from NCBI Genome Browser, and 1-kb DNA sequences upstream ATG were used as an input file for determining the transcriptional start sites (TSSs) for the retrieved genes. The Neural Network Promoter Prediction (NNPP version 2.2) tool set was used with the minimum standard predictive score (between 0 and 1) available at https://www.fruitfly.org/seq_tools/ promoter.html [20]. For those regions containing more than one TSS, the highest prediction score was considered.

\section{Motif discovery and comparison of the discovered motif against a database of known motifs}

Motif discovery was performed by MEME suite (Multiple $\mathrm{Em}$ for Motif Elicitation) software version 3.5.4 available at http://meme-suite. org/tools/meme using minimum and maximum motif width of 6 and $50 \mathrm{bp}$, respectively, and a maximum number of 3 motifs; the rest of the parameters were kept at default. The MEME output was shown in HTML, as well as in several other formats. The motif with the least $E$-value was used for comparison against a database of known motifs using TOMTOM and ranked the motifs in the database and produce an alignment for each significant match [21]. TOMTOM reported for each query a list of target motifs, ranked by $p$-value and $q$-value of each match [22]. TOMTOM also displayed putative transcription factors (TFs) that resemble the TFs of glucan endo-1,3-beta-glucosidase genes. Finally, after identification of those putative TFs interacting with DNA motif, the role of the TFs was described.

\section{$\mathrm{CpG}$ island analysis}

Sequences of 2000 bp upstream ATG for each glucan endo-1,3-beta-glucosidase gene of Solanum tuberosum cultivar DM 1-3 516 R44 were downloaded in FASTA format from NCBI (https://www.ncbi.nlm.nih.gov/), and the bioinformatics prediction of $\mathrm{CpG}$ islands was analyzed using CLC Genomics Workbench ver. 3.6.1 (available at http://clcbio.com, CLC bio, Aarhus, Denmark). Searching for MspI cutting sites (fragment sizes between 40 and $220 \mathrm{bp}$ ) is relevant for the detection of CGIs, because studies using whole genome CpG island libraries prepared for different species revealed that $\mathrm{CpG}$ islands

Table 1 List of the glucan endo-1,3-beta-glucosidase genes of Solanum tuberosum cultivar DM1-3 156R44 selected for analysis

\begin{tabular}{lll}
\hline S no & GI & Gene name \\
\hline 1 & ID: 102588651 & Glucan endo-1,3-beta-glucosidase 1-like \\
2 & ID: 102594958 & Glucan endo-1,3-beta-glucosidase-like \\
4 & ID: 102601393 & Glucan endo-1,3-beta-glucosidase 12-like \\
5 & ID: 102595473 & Glucan endo-1,3-beta-glucosidase-acidic isoform G19 \\
6 & ID: 102593331 & Glucan endo-1,3-beta-glucosidase-like protein 3-like \\
7 & ID: 102578898 & Glucan endo-1,3-beta-glucosidase 13 like \\
8 & ID: 102583593 & Glucan endo-1,3-beta-glucosidase 11-like \\
9 & ID: 102595860 & Glucan endo-1,3-beta-glucosidase 12-like \\
10 & ID:102605560 & Glucan endo-1,3-beta-glucosidase, basic isoform 1 \\
11 & ID: 102601178 & Glucan endo-1,3-beta-glucosidase 4 \\
12 & ID:102587248 & Glucan endo-1,3-beta-glucosidase 13-like \\
13 & ID: 102604922 & Glucan endo-1,3-beta-glucosidase 14 like \\
14 & ID: 102605428 & Glucan endo 1,3-beta-glucosidase, acidic isoform PR-Q'-like \\
15 & ID: 102596927 & Glucan endo 1,3-beta-glucosidase, acidic isoform PR-Q' \\
16 & ID: 102583800 & Glucan endo-1,3-beta-glucosidase 11-like \\
17 & ID: 102581946 & Glucan endo-1,3-beta-glucosidase 2-like \\
18 & ID: 102578810 & Glucan endo-1,3-beta-glucosidase 12-like \\
19 & ID: 102595638 & Glucan endo-1,3-beta-glucosidase-like protein 3-like
\end{tabular}


are not randomly distributed but are concentrated in particular regions, because CpG-rich regions are achieved by isolation of short fragments after MspI digestion that recognizes CCGG sites [23]. The parameter setting was as follows, with a guanine and cytosine (GC) content greater than or equal to $55 \%$ and observed to expected CpG ratio (Obs CpG/ExpCpG) greater than or equal to 0.65 and length $\geq 500 \mathrm{bp}$ [24].

\section{Mining glucan endo-1,3-beta-glucosidase genes for simple sequence repeats}

The 19 query sequences of glucan endo-1,3-beta-glucosidase genes of Solanum tuberosum cultivar DM 1-3 516 R44 were screened to detect di-, tri-, tetra-, penta-, and hexanucleotide simple sequence repeat (SSR) motifs using the SSRIT tool available at Gramene database (http://www.gramene.org/db/searches/ssrtool). After a thorough examination, the output was generated with details of the repeat motif, number of repeat units, repeat length, SSR start, and SSR end point [25].

\section{Phylogenetic relationship analysis}

The phylogenetic analysis was inferred using the UPGMA method [26]. The analysis involved 40 glucan endo-1,3-beta-glucosidase gene sequences selected from
Solanum tuberosum, Nicotiana tabacum, Solanum lycopersicum, and Arabidopsis thaliana [26]. The genetic distances were computed using the p-distance method [27]. Codon positions included were $1 \mathrm{st}+2 \mathrm{nd}+3 \mathrm{rd}+\mathrm{Non}-$ coding. All ambiguous positions were removed for each sequence pair (pairwise deletion option). The phylogenetic analysis, genetic distances, conserved sites, variable sites, and base composition of the gene sequences were conducted using the Molecular Evolution Genetic Analysis X32 (MEGA X32) available at https://www. megasoftware.net/ [28].

\section{Results}

Finding of transcription start sites and determination of promoter sequence

Transcription start sites (TSSs) predicted for each of the 19 study subjects are presented in Table 2 . The prediction showed that the glucan endo-1,3-beta-glucosidase genes of Solanum tuberosum cultivar DM 1-3 516 R44 had TSSs ranging from 1 to 3 . The predictive score for the majority $16(84.2 \%)$ of the promoter regions was 0.90 and above. The highest promoter prediction score (1.0) was obtained for two gene sequences only (Pro102604922 and Pro-102581946) while the lowest promoter prediction score $(0.8)$ was obtained in none of

Table 2 Number and predictive score for glucan endo-1,3-beta-glucosidase genes of Solanum tuberosum cultivar DM 1-3 156 R44 TSSS

\begin{tabular}{|c|c|c|c|c|}
\hline Gene ID & $\begin{array}{l}\text { Corresponding promoter } \\
\text { region name }\end{array}$ & $\begin{array}{l}\text { Number of TSS } \\
\text { identified }\end{array}$ & $\begin{array}{l}\text { Predictive score at a } \\
\text { cutoff value of } 0.8\end{array}$ & $\begin{array}{l}\text { Location of the best TSS } \\
\text { upstream of the translation start site }\end{array}$ \\
\hline ID102588651 & Pro-102588651 & 1 & 0.99 & -849 \\
\hline ID102594958 & Pro-102594958 & 3 & $0.81,0.84, \mathbf{0 . 9 8}$ & -277 \\
\hline ID102601393 & Pro-102601393 & 1 & 0.94 & -79 \\
\hline ID102595473 & Pro-102595473 & 1 & 0.91 & -724 \\
\hline ID102593331 & Pro-102593331 & 1 & 0.98 & -379 \\
\hline ID102578898 & Pro-102578898 & 1 & 0.98 & -2900 \\
\hline ID102583593 & Pro-102583593 & 3 & $0.82,0.84, \mathbf{0 . 9 1}$ & -79 \\
\hline ID102595860 & Pro-102595860 & 1 & 0.94 & -1579 \\
\hline ID102605560 & Pro-102605560 & 2 & $0.81, \mathbf{0 . 9 3}$ & -522 \\
\hline ID102601178 & Pro-102601178 & 1 & 0.90 & -2125 \\
\hline ID102587248 & Pro-102587248 & 1 & 0.91 & -50 \\
\hline ID102604922 & Pro-102604922 & 3 & $0.82,0.93 .1 .00$ & -1402 \\
\hline ID102605428 & Pro-102605428 & 1 & 0.88 & -313 \\
\hline ID102596927 & Pro-102596927 & 2 & $0.82, \mathbf{0 . 9 9}$ & -429 \\
\hline ID102583800 & Pro-102583800 & 1 & 0.81 & -348 \\
\hline ID102581946 & Pro-102581946 & 1 & 1.00 & -694 \\
\hline ID102578810 & Pro-102578810 & 3 & $0.86,0.94, \mathbf{0 . 9 7}$ & -1880 \\
\hline ID102595638 & Pro-102595638 & 3 & $0.83,0.85, \mathbf{0 . 9 3}$ & -751 \\
\hline ID102589208 & Pro-102589208 & 1 & 0.87 & -686 \\
\hline
\end{tabular}

${ }^{a}$ NNPP tool prediction result is considered reliable at 0.8 cutoff values for eukaryote organism [20]. Values in bold are the highest prediction scores for sequences having multiple TSS 
them (Table 2). In addition, the result of promoter predictions for glucan endo-1,3-beta-glucosidase gene sequences with a cutoff value of 0.80 showed that the majority $12(63.2 \%)$ of the gene sequences showed only one TSS, while $7(36.8 \%)$ of them revealed multiple TSSs.

In general, the TSSs of gene sequences were located between the range of -79 and $-2900 \mathrm{bp}$ relative to the translation start codon (ATG), with a relatively highest occurrence in the region above -1000 bp (5 sequences), followed by -201 to $-400 \mathrm{bp}$ and -601 to $-800 \mathrm{bp}$ regions (4 sequences, each), -1 to $-200 \mathrm{bp}$ ( 3 sequences), and -401 to -600 ( 2 sequences), while the lowest occurrence was observed at -801 to -1000 bp (1 sequence).

\section{Discovery of common motifs and associated TFs in the promoter regions}

In the current study, five candidate motifs that were shared by glucan endo-1,3-beta-glucosidase gene promoter sequences of Solanum tuberosum cultivar DM 1-3 516 R44 were discovered (Table 3). The relative location and spatial distribution of the majority of the discovered common motifs were concentrated between +1 and -500 bp of the TSSs. MEME generated common candidate motifs for $18 / 19$ of the gene promoter sequences. It is also interesting to notice that the discovered motifs were distributed on both positive and negative strands with 30 and 25, respectively, as shown in Fig. 1.

To determine a candidate common promoter motif which is functionally important, a motif which was shared by the majority of promoter regions of Solanum tuberosum glucan endo-1,3-beta-glucosidase genes was selected. Among the five motifs, M $\beta G$ II was identified as a common promoter motif shared by $94.4 \%$ of Solanum tuberosum glucan endo-1,3-beta-glucosidase promoters. A common promoter motif serves as binding sites for transcription factors involved in gene expression and regulation of these genes. A sequence logo for M $\beta$ GII generated by MEME is presented in Fig. 2. Moreover, further analysis was carried out to get more information on the MBGII motif of the potato (Solanum tuberosum DM 1-3 156 R44) glucan endo-1,3-beta- glucosidase genes. Thus, M $\beta$ GII was compared to registered motifs in publicly available databases to see if they are similar to known regulatory motifs.

\section{Discovery of matches to the query motif}

Among the discovered five common candidate motifs, M $\beta$ GII with the $E$ value of $3.5 \mathrm{e}-001$ was used as a query motif for comparison against a database of JASPAR2018_CORE_vertebrates non-redundant uniprobe mouse of known motifs using TOMTOM web application [21]. The analysis showed that the query motif MBGII serves as binding sites for 8 transcription factors, namely, (MA0016.1(usp), MA0359.1(RAP1), MA0159,1(RARA: RXRA), MA1149.1 (RARA: RXRG), MA0258.2(ESR2), UP00070_2(Gcm1_ secondary), MA0450.1(hkb), and MA0801.1(MGA). As we tried to check the role of the identified TFs in the UniProt protein database, they act as a receptor to their target ligands, regulate gene expression in various biological processes and developments, involved in cell adhesion and cell junction formation, and act as a repressor or activator (Table 4).

\section{CpG island analysis}

In the present study, $\mathrm{CpG}$ island analysis of the promoter region was investigated using in silico digestion method (using restriction enzyme $M s p I$ ) and the result showed low CpG density in the investigated regions. Fragments were observed only in gene ID: 102593331 and 102595860 (Table 5). The presence of low-density CpG islands might be associated with selective gene expression at a specific tissue.

\section{SSR motif occurrence in sequences}

In the present study, 265 different SSR motifs ranging in size from 2 to 6 (dimer to hexamer) and in number from 2 to 9 per gene were detected in the gene sequences of Solanum tuberosum cultivar DM 1-3 516 R44 examined, shown in supplementary table 1 . Dimer motifs such as ac, at, ag, ca, ct, ga, gt, ta, and tc were found in the majority (95\%) of the gene sequences. Assuming the presence of a large number of tandem repeats, their effects

Table 3 Identified common candidate motifs in Solanum tuberosum DM 1-3 156 R44 glucan endo-1,3- beta-glucosidase gene promoter regions

\begin{tabular}{|c|c|c|c|c|}
\hline $\begin{array}{l}\text { Discovered candidate } \\
\text { motif }\end{array}$ & $\begin{array}{l}\text { Number (\%) of beta 1,3-glucosidase promoters containing each one } \\
\text { of the motifs }\end{array}$ & $E$-value ${ }^{a}$ & $\begin{array}{l}\text { Motif } \\
\text { width }\end{array}$ & $\begin{array}{l}\text { Total no. of binding } \\
\text { sites }\end{array}$ \\
\hline$\overline{M \beta G I}$ & 15 (83.3\%) & $3.6 e-010$ & 15 & 15 \\
\hline$M \beta G \|$ & 17 (94.4\%) & $3.5 e-001$ & 21 & 17 \\
\hline$M \beta G I I I$ & 10 (55.5\%) & $4.9 e+000$ & 21 & 10 \\
\hline MBGIV & 7 (38.8\%) & $9.6 e+002$ & 21 & 7 \\
\hline$M \beta G V$ & 6 (33.3\%) & 7.7e+002 & 28 & 6 \\
\hline
\end{tabular}

Probability of finding an equally well-conserved motif in random sequences 


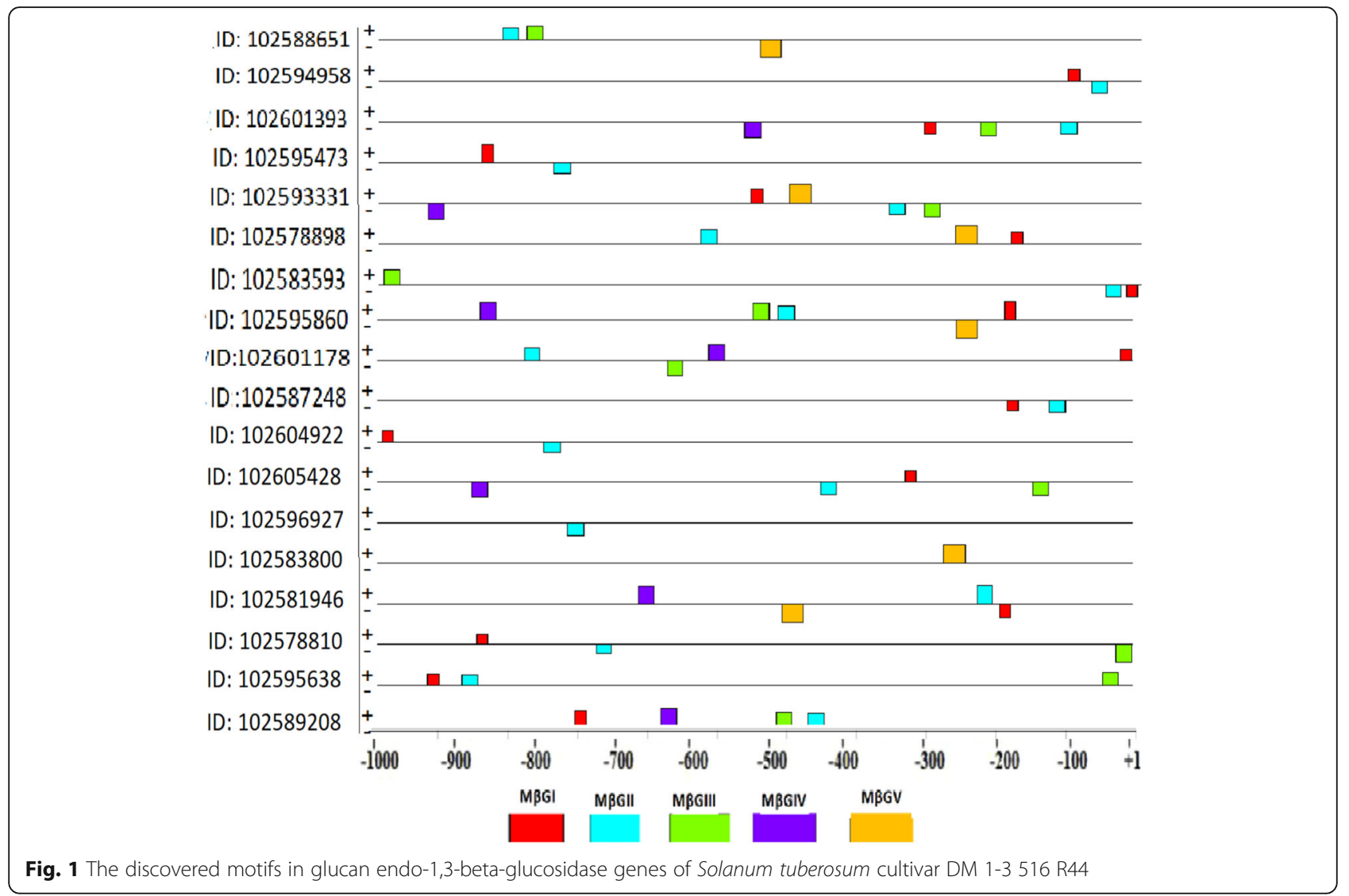

are likely to occur in the glucan endo-1,3-beta-glucosidase gene of Solanum tuberosum cultivar DM 1-3 516 R44. Gene sequences with the highest number of dimer repeats are shown in Table 6.

\section{Genetic divergence among gene sequences from different} plant species

The genetic distance was assessed using 40 gene sequences (supplementary table 2). A total of 5812 positions or sites were found in the final dataset. The genetic distance among the gene sequences ranged from 0.685 to 0.770 . Gene ID:102605428 and ID:102578810 recorded the least genetic distance (0.685); both are from the same species Solanum tuberosum. Meanwhile, the highest genetic distance (0.77) was estimated between ID:102581946 in Solanum tuberosum and ID:832156 in Arabidopsis thaliana and between ID:107820469 in Nicotiana_tabacum and ID:834215 in Arabidopsis thali$a n a$, each. The overall mean genetic distance was calculated as 0.73 , and this shows a narrower genetic

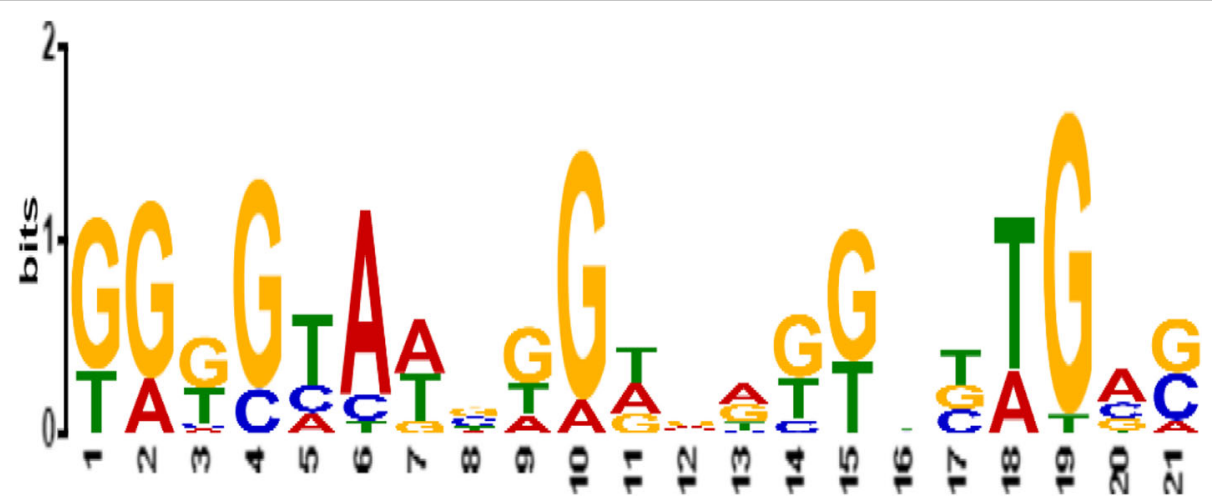

Fig. 2 Sequence logo for the identified common motif MBGll for glucan endo-1,3-beta-glucosidase genes of Solanum tuberosum cultivar DM1-3 156 R44 
Table 4 List of matches to the query motif from the database JASPAR2018_CORE_vertebrates_non redundant and Uniprobe mouse

\begin{tabular}{|c|c|c|c|c|c|c|c|}
\hline S & Match name & Data base & $E$-value & $\begin{array}{l}\text { Over } \\
\text { lap }\end{array}$ & Offset & Orientation & Function \\
\hline 1 & (MA0016.1(usp) & $\begin{array}{l}\text { JASPAR2018_ } \\
\text { CORE_vetebrates_ } \\
\text { non redundant }\end{array}$ & $1.91 \mathrm{e}-01$ & 10 & 0 & Normal & $\begin{array}{l}\text { Receptor for ecdysone. May be an important modulator of } \\
\text { insect metamorphosis. Plays an important part in embryonic } \\
\text { and post-embryonic development }\end{array}$ \\
\hline 2 & MA0359.1(RAP1) & $\begin{array}{l}\text { JASPAR2018_- } \\
\text { CORE_vetebrates_ } \\
\text { non redundant }\end{array}$ & $7.76 e-01$ & 10 & -2 & $\begin{array}{l}\text { Reverse } \\
\text { complement }\end{array}$ & $\begin{array}{l}\text { Rap1 is predominantly involved in cell adhesion and cell } \\
\text { junction formation. }\end{array}$ \\
\hline 3 & $\begin{array}{l}\text { MA0159,1(RARA:: } \\
\text { RXRA) }\end{array}$ & $\begin{array}{l}\text { JASPAR2018_ } \\
\text { CORE_vetebrates_ } \\
\text { non redundant }\end{array}$ & $1.25 \mathrm{e}+00$ & 17 & -1 & Normal & $\begin{array}{l}\text { Receptor for retinoic acid. Retinoic acid receptors bind as } \\
\text { heterodimers to their target response elements in response to } \\
\text { their ligands, all-trans or 9-cis retinoic acid, and regulate gene } \\
\text { expression in various biological processes. }\end{array}$ \\
\hline 4 & $\begin{array}{l}\text { MA1149.1 (RARA } \\
\because: \text { RXRG) }\end{array}$ & $\begin{array}{l}\text { JASPAR2018__ } \\
\text { CORE_vetebrates_ } \\
\text { non redundant }\end{array}$ & $2.24 e+00$ & 18 & 0 & Normal & $\begin{array}{l}\text { Receptor for retinoic acid. Retinoic acid receptors bind as } \\
\text { heterodimers to their target response elements in response to } \\
\text { their ligands, all-trans or 9-cis retinoic acid, and regulate gene } \\
\text { expression in various biological processes }\end{array}$ \\
\hline 5 & MA0258.2 (ESR2) & $\begin{array}{l}\text { JASPAR2018__ } \\
\text { CORE_vetebrates_ } \\
\text { non redundant }\end{array}$ & $3.76 \mathrm{e}+00$ & 15 & -1 & $\begin{array}{l}\text { Reverse } \\
\text { complement }\end{array}$ & Its molecular function is transcription, transcription regulation \\
\hline 6 & $\begin{array}{l}\text { UP00070_ } \\
\text { 2(Gcm1_- } \\
\text { secondary) }\end{array}$ & Uniprobe mouse & $6.48 \mathrm{e}+00$ & 17 & 0 & Normal & $\begin{array}{l}\text { The transcription factor glial cells missing } 1(\mathrm{Gcm} 1) \text { plays a } \\
\text { pivotal role in labyrinth development }\end{array}$ \\
\hline 7 & MA0450.1(hkb) & $\begin{array}{l}\text { JASPAR2018_ } \\
\text { CORE_vetebrates_ } \\
\text { non redundant }\end{array}$ & $9.09 e+00$ & 9 & -11 & Normal & $\begin{array}{l}\text { As a repressor, hkb assures that the formation of mesoderm } \\
\text { (by ventral invagination of the presumptive mesoderm) does } \\
\text { not spread to the two poles of the egg. }\end{array}$ \\
\hline 8 & MA0801.1 (MGA) & $\begin{array}{l}\text { JASPAR2018_ } \\
\text { CORE_vetebrates_ } \\
\text { non redundant }\end{array}$ & $9.30 \mathrm{e}+00$ & 8 & -12 & Normal & $\begin{array}{l}\text { Functions as a dual-specificity transcription factor, regulating } \\
\text { the expression of both MAX-network and T-box family target } \\
\text { genes. Functions as a repressor or an activator. }\end{array}$ \\
\hline
\end{tabular}

Table $5 \mathrm{Msp} /$ cutting sites and fragment sizes for glucan endo -1,3-beta-glucosidase genes in the promoter regions

\begin{tabular}{|c|c|c|c|}
\hline Region & $\begin{array}{l}\text { Gene ID of the corresponding glucan-1,3-beta- } \\
\text { glucosidase gene }\end{array}$ & Nucleotide positions of $M s p /$ sites & $\begin{array}{l}\text { Fragment sizes (between } 40 \\
\text { and } 220 \text { bps) }\end{array}$ \\
\hline \multirow{19}{*}{$\begin{array}{l}\text { Promoter } \\
\text { region }\end{array}$} & ID: 102588651 & No restriction & - \\
\hline & ID: 102594958 & No restriction & - \\
\hline & ID: 102601393 & No restriction & - \\
\hline & ID: 102595473 & No restriction & - \\
\hline & ID: 102593331 & Restrictions found (at 155 and 1440) & 155 \\
\hline & ID: 102578898 & No restriction & - \\
\hline & ID: 1025835931 & Single restriction (at 919) & - \\
\hline & ID: 102595860 & $\begin{array}{l}\text { Restrictions found (at 1062, 1066, 1134, } \\
\text { 1153, and 1318) }\end{array}$ & 68,165 \\
\hline & ID:102605560 & No restriction & - \\
\hline & ID: 102601178 & Single restriction (at 411) & - \\
\hline & ID:102587248 & No restriction & - \\
\hline & ID: 102604922 & No restriction & - \\
\hline & ID: 102605428 & Single restriction (at 1000) & - \\
\hline & ID: 102596927 & No restriction & - \\
\hline & ID: 102583800 & No restriction & - \\
\hline & ID: 102581946 & Single restriction (at 850) & - \\
\hline & ID: 102578810 & No restriction & - \\
\hline & ID: 102595638 & No restriction & - \\
\hline & ID: 102589208 & Single restriction (at 815) & _- \\
\hline
\end{tabular}


Table 6 Gene sequences with the highest number of dimer repeats

\begin{tabular}{llllll}
\hline Sequence & Motif & No. of repeats & SSR start & SSR end & Seq length \\
\hline ID: 102578898 & ac & 7 & 4361 & 4374 & 4566 \\
ID: 102595860 & ta & 9 & 1419 & 1436 & 2570
\end{tabular}

diversity range among the sequences. The distance matrix is shown in supplementary table 3.

\section{Phylogenetic relationships of glucan endo-1,3-beta- glucosidase gene sequences}

The phylogenetic tree resulted in seven clusters: cluster I comprised of 9 gene sequences, 3 from Nicotiana tabacum, 2 from Arabidopsis thaliana, 3 from Solanum tuberosum, and 1 from Solanum lycopersicum; cluster II comprised of 8 gene sequences, 5 from Nicotiana tabacum, 2 from Solanum tuberosum, and 1 from Solanum lycopersicum; cluster III comprised of 7 gene sequences, 5 from Solanum tuberosum, 1 from Nicotiana tabacum, and another 1 from Arabidopsis thaliana; cluster IV comprised of 4 gene sequences, 2 from Arabidopsis thaliana, 1 from Nicotiana tabacum, and 1 from Solanum tuberosum; cluster V consisted of 3 gene sequences entirely from Solanum tuberosum; cluster VI comprised of 4 gene sequences, 2 from Nicotiana tabacum, 1 from Solanum lycopersicum, and 1 from Solanum tuberosum; and cluster VII comprised of 2 gene sequences mainly from Solanum tuberosum. Meanwhile, two gene sequences from Solanum tuberosum and one from Arabidopsis thaliana were individually isolated from the clusters (Fig. 3).

\section{Multiple sequence alignment of the gene sequences}

The multiple sequence alignment was conducted using the Clustal Omega algorithm available online at https:// www.ebi.ac.uk/Tools/msa/. The result ranges from $24.4 \%$ (between ID107820469 and ID102605428) to 95.2\% (between ID107803828 and ID107824944) shown in supplementary table 4 . The number of conserved sites, variable sites, and the frequency of nucleotide bases is mentioned in Table 7. Gene ID102601178 in Solanum tuberosum had the lowest rate for both conserved sites and variable sites, accounting for $7.5 \%$ and $20.7 \%$, respectively, whereas gene ID102589208 in Solanum tuberosum had the greatest value (28.8\%) for conserved sites and gene ID832156 in Arabidopsis thaliana had the highest proportion $(76.1 \%)$ for variable sites.

\section{Discussion}

Finding of transcriptional start site (TSS) triggers the prediction of the promoter region and thus simplifies the subsequent analysis of gene expression. In the present in silico analysis, the number of TSSs per gene sequences was 1 to 3 , and the majority 12 (63.1\%) of the gene sequences had a single transcription start site, consistent with the previous finding by [29], who reported that $62.1 \%$ of the gene sequences contained single TSS. However, in most in silico analysis studies, it has been reported that most genes have more than one TSS [30$34]$. In the present study, it was also revealed that the locations for $42 \%$ of the TSSs were below -500 bp relative to the ATG. However, several authors reported that the location of the TSSs of the majority $(>50 \%)$ of the gene sequences studied was below -500 bp relative to ATG [35-38].

Patterns of gene expression (conditionally or temporally) have been linked to transcription regulation [39]. The common promoter motif is short DNA segments that serve as binding sites for TFs involved in gene expression regulation [31]. In the present study, the common promoter motif was found in 18 (94.4\%) of the promoter sequences investigated. Some studies reported the sharing of a common promoter motif by all the promoter sequences (100\%) [29, 32]. The discovery of matches to the query sequence showed that the query motif serves as binding sites for 8 transcription factors, involved in the regulation of gene expression as a receptor, transcription factor, or repressor in various biological processes (Table 4).

Several studies reported that CpG islands (CGIs) play an important role in the regulation of gene expression [40]. DNA of plant species has been shown to contain more CpG dinucleotides than human DNA [41]. Methylation of cytosine at $\mathrm{CpG}$ islands has been shown to restrict the access of promoter region of genes to their transcription factors, hence preventing their expression [42]. Consistent with the present analysis, low CpG content was reported in the promoter region of rice PR2 (beta 1,3-glucanase) genes but none is identified in the promoter region of all the families of Arabidopsis thaliana PR gene families [43]. The absence of CpG islands in glucan endo-1,3-beta-glucosidase gene (PR2) might be indicative of tissue-specific gene expression. Ferguson and Jiang [44] also showed that dicots such as potato genome contain low CpG density than monocots. Conversely, Gardiner-Garden and Frommer [45] reported that, in plants, high-density CpG islands tended to lie near the 5 '-ends (towards the promoter region) of housekeeping genes which is associated with broad expression of these genes.

In the current study, the cluster analysis showed that the gene sequences from different plant species 


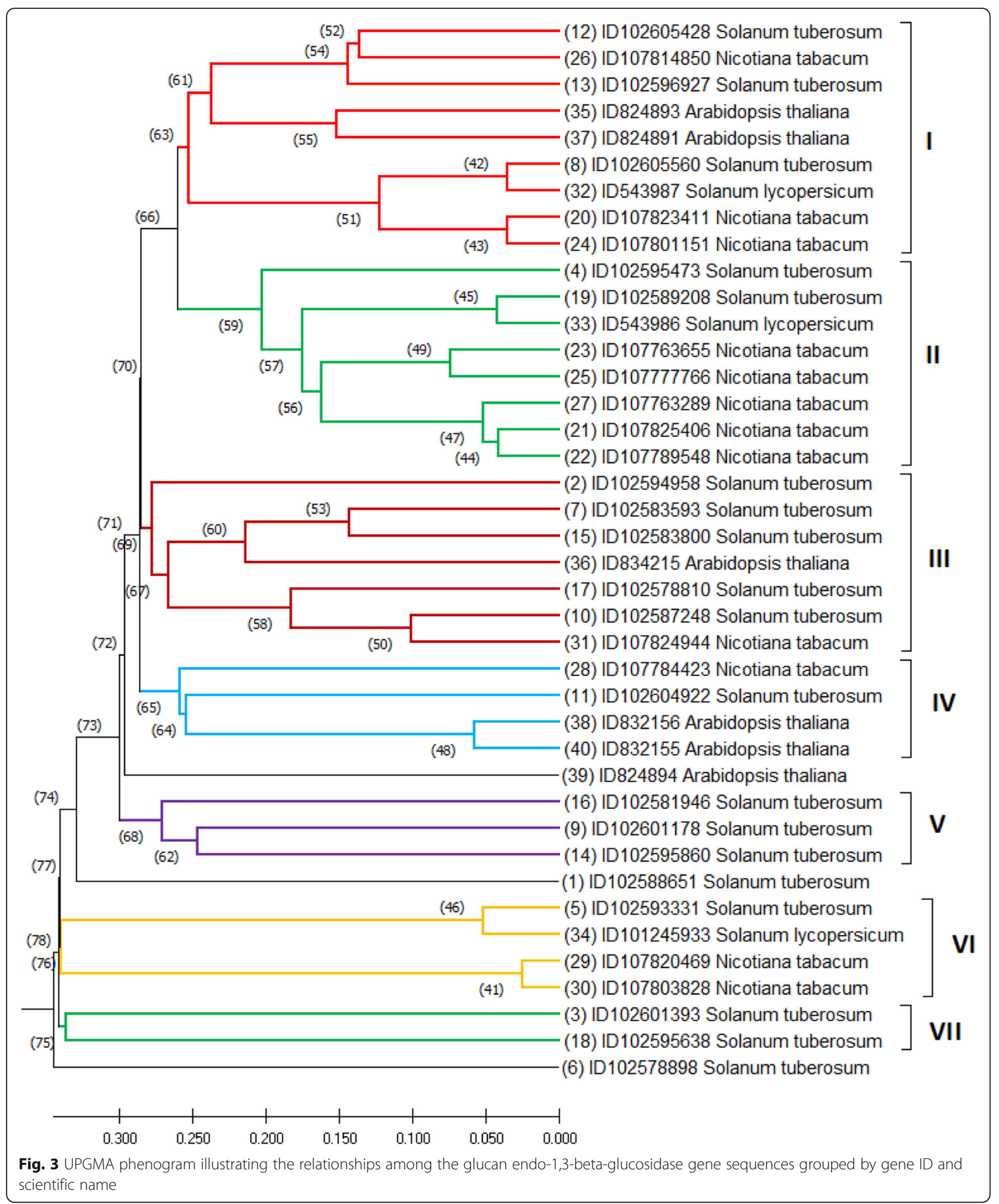

clustered together. In our results, the range of conserved sites was between 7.5 and $28.8 \%$ while the range of variable sites was between 20.7 and $76.1 \%$.
Though the percentage range of variable sites was wider than the conserved sites, the phylogeny showed the opposite relationship. 
Table 7 Number of conserved sites, variable sites, and frequency of each nucleotide

\begin{tabular}{|c|c|c|c|c|c|c|c|}
\hline Gene & bp & Conserved site & Variable site & $\mathrm{T}$ & C & A & G \\
\hline ID102588651 Solanum tuberosum & 1645 & $410(24.9 \%)$ & $1235(75 \%)$ & 34.7 & 17.8 & 29 & 18.3 \\
\hline ID102594958 Solanum tuberosum & 2928 & $415(14.1 \%)$ & $1230(42 \%)$ & 33.7 & 17.4 & 30 & 18.7 \\
\hline ID102601393 Solanum tuberosum & 1969 & $461(23.4 \%)$ & $1184(60 \%)$ & 34.5 & 20.1 & 29.7 & 15.5 \\
\hline ID102595473 Solanum tuberosum & 1587 & $418(26.3 \%)$ & 1169 (73\%) & 34.4 & 15.8 & 32.7 & 17 \\
\hline ID102593331 Solanum tuberosum & 3721 & 447 (12\%) & 1198 (32.1\%) & 36 & 16.6 & 30.7 & 16.5 \\
\hline ID102578898 Solanum tuberosum & 4566 & $481(10.5 \%)$ & $1164(25.4 \%)$ & 35.7 & 17.7 & 27.8 & 18.6 \\
\hline ID102583593 Solanum tuberosum & 1378 & $369(26.7 \%)$ & 1009 (73.2\%) & 29.3 & 26.6 & 25.1 & 18.8 \\
\hline ID102605560 Solanum tuberosum & 1545 & $438(28.3 \%)$ & $1107(71.6 \%)$ & 32.1 & 17.8 & 30.2 & 19.7 \\
\hline ID102601178 Solanum tuberosum & 5812 & $441(7.5 \%)$ & 1204 (20.7\%) & 36.7 & 16.8 & 26.9 & 19.4 \\
\hline ID102587248 Solanum tuberosum & 1740 & $388(22.2 \%)$ & $1257(72.2 \%)$ & 31.6 & 20 & 26.8 & 21.4 \\
\hline ID102604922 Solanum tuberosum & 5363 & $432(8 \%)$ & $1213(22.6 \%)$ & 37 & 17.5 & 25.8 & 19.5 \\
\hline ID102605428 Solanum tuberosum & 1360 & $374(27.5 \%)$ & $986(72.5 \%)$ & 29.2 & 20.6 & 31.1 & 18.8 \\
\hline ID102596927 Solanum tuberosum & 2460 & $444(18 \%)$ & $1201(48.8 \%)$ & 32.6 & 18.1 & 31.6 & 17.6 \\
\hline ID102595860 Solanum tuberosum & 2570 & $421(16.3 \%)$ & $1224(47.6 \%)$ & 33.8 & 16.7 & 30.9 & 18.4 \\
\hline ID102583800 Solanum tuberosum & 1920 & $446(23.2 \%)$ & $1199(62.4 \%)$ & 31.9 & 22.5 & 25.2 & 20.2 \\
\hline ID102581946 Solanum tuberosum & 3960 & $434(10.9 \%)$ & $1211(30.5 \%)$ & 34.2 & 18.6 & 27.8 & 19.2 \\
\hline ID102578810 Solanum tuberosum & 2778 & $440(15.8 \%)$ & $1205(43.3 \%)$ & 35.4 & 19.3 & 25.8 & 19.4 \\
\hline ID102595638 Solanum tuberosum & 3982 & $431(10.8 \%)$ & $1214(30.4 \%)$ & 38.8 & 16.8 & 27.8 & 16.3 \\
\hline ID102589208 Solanum tuberosum & 1608 & $464(28.8 \%)$ & $1144(71.1 \%)$ & 34.5 & 16.7 & 32.7 & 15.9 \\
\hline ID107823411 Nicotiana tabacum & 2207 & $456(20.6 \%)$ & $1189(53.8 \%)$ & 33.6 & 18.5 & 29.7 & 18 \\
\hline ID107825406 Nicotiana tabacum & 1967 & $465(23.6 \%)$ & 1180 (59.9\%) & 34.1 & 18 & 29.8 & 17.9 \\
\hline ID107789548 Nicotiana tabacum & 1814 & $435(23.9 \%)$ & $1210(66.7 \%)$ & 35 & 17.9 & 30.3 & 16.7 \\
\hline ID107763655 Nicotiana tabacum & 2012 & $410(20.3 \%)$ & $1235(61.3 \%)$ & 34.2 & 18.2 & 31.2 & 16.2 \\
\hline ID107801151 Nicotiana tabacum & 2189 & $461(21 \%)$ & $1184(54 \%)$ & 34 & 18.5 & 29.5 & 17.8 \\
\hline ID107777766 Nicotiana tabacum & 2034 & $445(21.8 \%)$ & $1200(58.9 \%)$ & 34.1 & 17.7 & 31.9 & 16.1 \\
\hline ID107814850 Nicotiana tabacum & 1809 & $466(25.7 \%)$ & 1179 (65.1\%) & 29.1 & 19.5 & 30.4 & 20.7 \\
\hline ID107763289 Nicotiana tabacum & 1671 & $437(26.1 \%)$ & $1208(72.2 \%)$ & 34.3 & 18.6 & 30.5 & 16.4 \\
\hline ID107784423 Nicotiana tabacum & 1630 & $432(26.5 \%)$ & 1198 (73.4\%) & 34.4 & 19.1 & 28.2 & 18.2 \\
\hline ID107820469 Nicotiana tabacum & 1311 & $342(26 \%)$ & $969(73.9 \%)$ & 37.2 & 15 & 29.9 & 17.8 \\
\hline ID107803828 Nicotiana tabacum & 2607 & $411(15.7 \%)$ & $1234(47.3 \%)$ & 33.1 & 19.6 & 27.7 & 19.4 \\
\hline ID107824944 Nicotiana tabacum & 1305 & $332(25.4 \%)$ & $973(74.5 \%)$ & 28.4 & 24.5 & 26.2 & 20.7 \\
\hline ID543987 Solanum lycopersicum & 2025 & $453(22.3 \%)$ & $1192(58.8 \%)$ & 34.5 & 16.7 & 31 & 17.6 \\
\hline ID543986 Solanum lycopersicum & 1717 & $479(27.8 \%)$ & 1166 (67.9\%) & 34.6 & 16.5 & 33.1 & 15.6 \\
\hline ID101245933 Solanum lycopersicum & 3858 & $452(11.7 \%)$ & $1193(30.9 \%)$ & 37.5 & 16.5 & 30.5 & 15.2 \\
\hline ID824893 Arabidopsis thaliana & 1571 & $423(26.9 \%)$ & $1148(73 \%)$ & 27.6 & 20.9 & 29.4 & 22 \\
\hline ID834215 Arabidopsis thaliana & 2506 & $423(16.8 \%)$ & $1222(48.7 \%)$ & 30.4 & 24.8 & 24.7 & 19.9 \\
\hline ID824891 Arabidopsis thaliana & 1503 & $430(28.6 \%)$ & $1073(71.3 \%)$ & 28 & 22.5 & 28.1 & 21.2 \\
\hline ID832156 Arabidopsis thaliana & 1140 & $272(23.8 \%)$ & $868(76.1 \%)$ & 26.8 & 24.2 & 28 & 20.7 \\
\hline ID824894 Arabidopsis thaliana & 1953 & $459(23.5 \%)$ & 1186 (60.7\%) & 31.6 & 18.5 & 32.4 & 17.3 \\
\hline ID832155 Arabidopsis thaliana & 1602 & $409(25.5 \%)$ & $1193(74.4 \%)$ & 28.3 & 22.6 & 28.9 & 20 \\
\hline
\end{tabular}

In the present study, the SSR motifs ranged in size from 2 to 6 (dimer to hexamer), and the number of SSR motifs per gene ranged from 2 to 9 . The SSR motif analysis also revealed that there is lack of significant variation in the repetition number of the SSR motifs between gene sequences of the different plant species and lack of differences within the repetitive SSR motifs between gene sequences within species. As it is already 
known, the presence of SSRs within genes can lead to (i) a gain or loss of gene function, (ii) affect transcription and translation, (iii) mRNA splicing, or (iv) export to the cytoplasm. All these effects eventually lead to phenotypic changes [42]. Most often, the length of the simple sequence repeat (SSR) motif does not exceed nine nucleotides and is referred to as short tandem repeats (STRs) or SSRs, or microsatellites. Short tandem repeats are associated with a higher frequency of mutation, affecting DNA sequence composition and length [46].

CGIs are known to concentrate near the transcription start sites (TSSs) of genes. Genes that possess CGIs are often highly expressed in multiple tissues. In the current study, CpG island analysis of the promoter region showed a low density of CpG islands. Possibly, low CpG island density could be one reason for the lack of divergence between gene sequences. According to Prendergast et al. [47], CpG island poor regions are not subjected to evolutionary divergence. Moreover, due to the lack of significant differences in the number of repetitions of SSR motifs between gene sequences of the different plant species and lack of differences within the repetitive SSR motifs between gene sequences within species, the phylogenetic analysis did not show a clear and defined phylogenetic relationship. Therefore, further analysis of CpG islands and their convergence into TSSs of genes and involvement in evolutionary divergence will pave the way for a greater understanding of their roles in gene expression and gene evolution.

\section{Conclusion}

The major aim of this work was to explore regulatory elements that can determine the expression of glucan endo-1,3-beta-glucosidase genes of Solanum tuberosum cultivar DM 1-3 516 R44. Consequently, the study showed transcription factors that serve as receptors, activators, and/or repressors of glucan endo-1,3-beta-glucosidase gene. In addition, transcription start sites, promoter regions, SSR motifs, and CpG islands in glucan endo-1,3-beta-glucosidase gene that plays role in the process of gene expression regulation were identified. The phylogenetic analysis revealed that the clustering patterns of the gene sequences were not entirely based on taxa. In general, this in silico analysis would allow for the understanding of regulatory mechanisms involved in glucan endo-1,3-beta-glucosidase gene expression and helps to identify gene regulatory elements in the promoter regions.

\section{Abbreviations}

TSS: Transcription start site; M $\beta G$ ll: Motif of beta-glucosidase;

TFs: Transcription factors; SSR: Simple sequence repeat; MEME: Multiple em for motif elicitation; NCBI: National center for biotechnology information; bp: Base pair; NNPP: Neural network promoter prediction

\section{Supplementary Information}

The online version contains supplementary material available at https://doi. org/10.1186/s43141-021-00240-0.

Additional file 1: Supplementary table 1 SSR motif occurrences by gene sequences

Additional file 2: Supplementary table $\mathbf{2}$ List of the glucan endo-1,3beta -glucosidase gene sequences from different plant species

Additional file 3: Supplementary table 3 Genetic distance matrix

Additional file 4: Supplementary table 4 Data matrix of the multiple sequence alignment

Acknowledgements

The authors acknowledge Adama Science and Technology University, School of Applied Natural Science, for funding the research.

\section{Authors' contributions}

AK designed and performed the experiment, analyzed the data, prepared the draft manuscript, and is the correspondence of the paper. MK designed the experiment, supervised the research, and revised the manuscript. The authors read and approved the final manuscript.

\section{Funding}

This work was financially supported by the graduate program of Adama Science and Technology University.

\section{Availability of data and materials}

The qualitative and quantitative data of this manuscript are available through the first author.

\section{Declarations}

Ethics approval and consent to participate

Not applicable

Consent for publication

Not applicable

Competing interests

The authors declare that they have no competing interests.

Received: 18 May 2021 Accepted: 2 September 2021

Published online: 30 September 2021

\section{References}

1. Skog K, Viklund G (2014) Processing contaminants: acrylamide. Encyclopedia Food Saf 2:363-370. https://doi.org/10.1016/B978-0-12-378612-8.00206-7

2. Kuete $V$ (2014) Health effects of alkaloids from African medicinal plants. Toxicol Surv Afr Med Plants 611-633. https://doi.org/https://doi.org/10.1016/ B978-0-12-800018-2.00021-2

3. Agrios GN (2005) Plant Patholology. 5th edn. Elsevier-Academic press, San Diego

4. Mauch F, Hadwiger LA, Boller T (1988) Antifungal hydrolases in pea tissue: I. purification and characterization of two chitinases and two $\beta-1,3-$ glucanases differentially regulated during development and in response to fungal infection. Plant Physiol 87(2):325-333. https://doi.org/0032-0889/88/ 87/0325/09/\$01 00/0. https://doi.org/10.1104/pp.87.2.325

5. Vogelsang R, Barz W (1993) Purification, characterization and differential hormonal regulation of a $\beta-1,3$-glucanase and two chitinases from chickpea (Cicer arietinum L.). Planta 189(1):60-69. https://doi.org/https://doi. org/10.1007/BF00201344

6. Jach G, Görnhardt B, Mundy J, Logemann J, Pinsdorf E, Leah R, Schell J, Maas C (1995) Enhanced quantitative resistance against fungal disease by combinatorial expression of different barley antifungal proteins in transgenic tobacco. Plant J 8(1):97-109. https://doi.org/https://doi.org/10.104 6/j.1365-313X.1995.08010097.x

7. Bettini P, Cosi E, Pellegrini MG, Turbanti L, Vendramin G, Buiatti M (1998) Modification of competence for in vitro response to Fusarium oxysporum in tomato cells. III. PR-protein gene expression and ethylene evolution in 
tomato cell lines transgenic for phytohormone-related bacterial genes. Theor Appl Gene 97(4):575-583. https://doi.org/https://doi.org/10.1007/ s001220050933

8. Lambais MR, Mehdy MC (1998) Spatial distribution of chitinases and $\beta-1,3$ glucanase transcripts in bean arbuscular mycorrhizal roots under low and high soil phosphate conditions. New Phytol 140(1):33-42. https://doi.org/ https://doi.org/10.1046/j.1469-8137.1998.00259.x

9. Petruzzelli L, Kunz C, Waldvogel R, Meins Jr F, Leubner-Metzger G (1999) Distinct ethylene-and tissue-specific regulation of $\beta-1,3-$ glucanases and chitinases during pea seed germination. Planta. 209(2):195-201. https://doi. org/https://doi.org/10.1007/s004250050622

10. Cheong YH, Kim CY, Chun HJ, Moon BC, Park HC, Kim JK, Lee SH, Han CD, Lee SY, Cho MJ (2000) Molecular cloning of a soybean class III $\beta-1,3-$ glucanase gene that is regulated both developmentally and in response to pathogen infection. Plant Sci 154(1):71-81. https://doi.org/10.1016/S0168-94 52(00)00187-4

11. Li WL, Faris JD, Muthukrishnan S, Liu DJ, Chen PD, Gill BS (2001) Isolation and characterization of novel cDNA clones of acidic chitinases and $\beta-1,3-$ glucanases from wheat spikes infected by Fusarium graminearum. Theor Appl Gene 102(2-3):353-362. https://doi.org/https://doi.org/10.1007/s00122 0051653

12. Doxey AC, Yaish MW, Moffatt BA, Griffith M, McConkey BJ (2007) Functional divergence in the Arabidopsis $\beta$-1, 3-glucanase gene family inferred by phylogenetic reconstruction of expression states. Mol Biol Evol 24(4):10451055. https://doi.org/https://doi.org/10.1093/molbev/msm024

13. Pitson SM, Seviour RJ, McDougall BM (1993) Noncellulolytic fungal $\beta$ glucanases: their physiology and regulation. Enzyme Microb Technol 15(3): 178-192. https://doi.org/https://doi.org/10.1016/0141-0229(93)90136-P

14. Confortin TC, Spannemberg SS, Todero I, Luft L, Brun T, Alves EA, Kuhn RC, Mazutti MA (2019) Microbial enzymes as control agents of diseases and pests in organic agriculture. New Future Dev Microbial Biotechnol Bioeng 321-332. https://doi.org/https://doi.org/10.1016/B978-0-444-63 504-4.00021-9

15. Beerhues L, Kombrink E (1994) Primary structure and expression of mRNAs encoding basic chitinase and 1, 3- $\beta$-glucanase in potato. Mol Plant Pathol 24(2):353-367. https://doi.org/https://doi.org/10.1007/BF00020173

16. Ignatius SM, Chopra RK, Muthukrishnan S (1994) Effects of fungal infection and wounding on the expression of chitinases and $\beta-1,3$ glucanases in near-isogenic lines of barley. Physiol Plant 90(3):584-592. https://doi.org/1 0.1111/j.1399-3054.1994.tb08818.x

17. Lozovaya W, Waranyuwat A, Widholm JM (1998) B-I, 3-Glucanase and resistance to Aspergillus flavus infection in maize. Crop Sci 38(5):1255-1260. https://doi.org/https://doi.org/10.2135/cropsci1998.0011183X003800050024x

18. Hanselle T, Barz W (2001) Purification and characterisation of the extracellular PR-2b $\beta$-1, 3-glucanase accumulating in different Ascochyta rabiei-infected chickpea (Cicer arietinum L.) cultivars. Plant Science 161(4): 773-781. https://doi.org/https://doi.org/10.1016/S0168-9452(01)00468-X

19. Zemanek AB, Ko TS, Thimmapuram J, Hammerschlag FA, Korban SS (2001) Changes in $\beta-1,3$-glucanase mRNA levels in peach in response to treatment with pathogen culture filtrates, wounding, and other elicitors. J Plant Physiol 159(8):877-889. https://doi.org/https://doi.org/10.1078/0176-1617-00779

20. Reese MG (2001) Application of a time-delay neural network to promoter annotation in the Drosophila melanogaster genome. Comput Chem 26(1): 51-56. https://doi.org/10.1016/S0097-8485(01)00099-7

21. Gupta S, Stamatoyannopoulos JA, Bailey TL, Noble WS (2007) Quantifying similarity between motifs. Genome Biol 8(2):1-9. https://doi.org/https://doi. org/10.1186/gb-2007-8-2-r24

22. Bailey TL, Boden M, Buske FA, Frith M, Grant CE, Clementi L, Ren J, Li WW, Noble WS (2009) MEME SUITE: tools for motif discovery and searching. Nucleic Acids Res 37(suppl_2): W202-W208. https://doi.org/https://doi.org/ $0.1093 /$ nar/gkp335

23. Takamiya T, Hosobuchi S, Asai K, Nakamura E, Tomioka K, Kawase M Kakutani T, Paterson AH, Murakami Y, Okuizumi H (2006) Restriction landmark genome scanning method using isoschizomers (Mspl/Hpall) for DNA methylation analysis. Electrophoresis 27(14):2846-2856. https://doi.org/ https://doi.org/10.1002/elps.200500776

24. Takai D, Jones PA (2002) Comprehensive analysis of CpG islands in human chromosomes 21 and 22. Proc Natl Acad Sci 99(6):3740-3745. https://doi. org/https://doi.org/10.1073/pnas.052410099

25. Temnykh S, DeClerck G, Lukashova A, Lipovich L, Cartinhour S, McCouch S (2001) Computational and experimental analysis of microsatellites in rice
(Oryza sativa L.): frequency, length variation, transposon associations, and genetic marker potential. Genome Res 11(8):1441-1452. https://doi.org/1 0.1101/gr.184001

26. Sneath P.H.A. and Sokal R.R. (1973). Numerical taxonomy. Freeman, San Francisco

27. Nei M, Kumar S (2000) Molecular evolution and phylogenetics. Oxford university press, New york

28. Kumar S, Stecher G, Li M, Knyaz C, Tamura K (2018) MEGA X: molecular evolutionary genetics analysis across computing platforms. Mol Biol Evol 35(6):1547-1549. https://doi.org/https://doi.org/10.1093/ molbev/msy096

29. Yirgu M, Kebede M (2019) Analysis of the promoter region, motif and CpG islands in AraC family transcriptional regulator ACP92 genes of Herbaspirillum seropedicae. Adv Biosci Biotechnol 10(6):150-164. https://doi. org/10.4236/abb.2019.106011

30. Halees AS, Leyfer D, Weng Z (2003) PromoSer: a large-scale mammalian promoter and transcription start site identification service. Nucleic Acids Res 31(13):3554-3559. https://doi.org/https://doi.org/10.1093/nar/gkg549

31. Das MK, Dai HK. (2007) A survey of DNA motif finding algorithms. BMC Bioinformatics 8(7):1-3. https://doi.org/https://doi.org/10.1186/1471-2105-8S7-S21

32. Dinka H, Milkesa A (2020) Unfolding SARS-CoV-2 viral genome to understand its gene expression regulation. Infect Genet Evol 84:104386. https://doi.org/https://doi.org/10.1016/j.meegid.2020.104386

33. Bantihun G, Kebede M (2021) In silico analysis of promoter region and regulatory elements of mitogenome co-expressed trn gene clusters encoding for bio-pesticide in entomopathogenic fungus, Metarhizium anisopliae: strain ME1. J Genet Eng Biotechnol. 19(1):1-11. https://doi.org/ https://doi.org/10.1186/s43141-021-00191-6

34. Beshir JA, Kebede M (2021) In silico analysis of promoter regions and regulatory elements (motifs and CpG islands) of the genes encoding for alcohol production in Saccharomyces cerevisiaea S288C and Schizosaccharomyces pombe 972h. J Genet Eng Biotechnol. 19(1):1-14. https://doi.org/https://doi.org/10.1186/s43141-020-00097-9

35. Chen SH, Zhou S, Tan J, Schachter H (1998) Transcriptional regulation of the human UDP-GIcNAc: alpha-6-D-mannoside beta-1-2-Nacetylglucosaminyltransferase II gene (MGAT2) which controls complex Nglycan synthesis. Glycoconj J 15(3):301-308. https://doi.org/https://doi.org/1 0.1023/A:1006957331273

36. Michaloski JS, Galante PA, Malnic B (2006) Identification of potential regulatory motifs in odorant receptor genes by analysis of promoter sequences. Genome Res 16(9):1091-1098. https://doi.org/10.1101/gr.51854 06

37. Zhang W, Tian Z, Sha S, Cheng LY, Philipsen S, Tan-Un KC (2011) Functional and sequence analysis of human neuroglobin gene promoter region. Biochim Biophys Acta Gene Regul Mech. 1809(4-6):236-244. https://doi.org/ https://doi.org/10.1016/j.bbagrm.2011.02.003

38. Samuel B, Dinka H (2020) In silico analysis of the promoter region of olfactory receptors in cattle (Bos indicus) to understand its gene regulation. Nucleosides Nucleotides Nucleic Acids 39(6):853-865. https://doi.org/https:// doi.org/10.1080/15257770.2020.1711524

39. Ueda HR, Chen W, Adachi A, Wakamatsu H, Hayashi S, Takasugi T, Nagano M, Nakahama Kl, Suzuki Y, Sugano S, lino M (2002) A transcription factor response element for gene expression during circadian night. Nature 418(6897):534-539. https://doi.org/https://doi.org/10.1038/nature00906

40. Deaton AM, Bird A. (2011) CpG islands and the regulation of transcription. Genes Dev 25(10):1010-1022. http://www.genesdev.org/cgi/doi/https://doi. org/10.1101/gad.2037511.

41. Ashikawa I (2001) Gene-associated CpG islands in plants as revealed by analyses of genomic sequences. The Plant Journal 26(6):617-625. https://doi. org/10.1046/j.1365-313x.2001.01062.x

42. Lim DH, Maher ER (2011). DNA methylation: a form of epigenetic control of gene expression. Obstet Gynaeco 12(1):37-42. https://doi.org/https://doi. org/10.1576/toag.12.1.037.27556

43. Kaur A, Pati PK, Pati AM, Nagpal AK (2017) In-silico analysis of cis-acting regulatory elements of pathogenesis-related proteins of Arabidopsis thaliana and Oryza sativa. PloS one. 12(9): e0184523. https://doi.org/https:// doi.org/10.1371/journal.pone.0184523

44. Ferguson AA, Jiang N (2011) Pack-MULEs, recycling and reshaping genes through GC-biased acquisition. Mob Genet Elements 1(2):135-138. https:// doi.org/https://doi.org/10.4161/mge.1.2.16948 
45. Gardiner-Garden M, Frommer M (1992) Significant CpG-rich regions in angiosperm genes. J. Mol. Evol. 34 (3):231-245. https://doi.org/https://doi. org/10.1007/BF00162972

46. Jansen A, Gemayel R, Verstrepen KJ (2012) Unstable microsatellite repeats facilitate rapid evolution of coding and regulatory sequences. Repetitive DNA 7:108-125. https://doi.org/https://doi.org/10.1159/000337121

47. Prendergast JG, Campbell H, Gilbert N, Dunlop MG, Bickmore WA, Semple CA (2007) Chromatin structure and evolution in the human genome. BMC Evol Biol 7(1):1-2. https://doi.org/https://doi.org/10.1186/1471-2148-7-72

\section{Publisher's Note}

Springer Nature remains neutral with regard to jurisdictional claims in published maps and institutional affiliations.

Submit your manuscript to a SpringerOpen ${ }^{\circ}$ journal and benefit from:

- Convenient online submission

- Rigorous peer review

- Open access: articles freely available online

- High visibility within the field

- Retaining the copyright to your article

Submit your next manuscript at $\boldsymbol{\nabla}$ springeropen.com 